\title{
Popüler Teknoloji Kavramlarının Eğitiminde Görsel Materyal Geliştirme Çalışması*
}

\section{Nasip DEMİRUŞ**, Erhan ACAR***, Salih GÜLEN****}

Öz: Bu çalışmanın amacı, popüler teknoloji kavramlarını içeren 72 tane film ve belgeselden elde edilen kavramların daha iyi öğrenilmesi ve verimli bir şekilde algılanabilir hale getirilmesi için sanal programlarla daha fazla duyuya hitap edecek şekilde materyal hazırlamaktır. Materyal, görsel, işitsel, yazımsal ve zamansal olarak daha çok duyuya hitap edecek, internet ve çok amaçlı disk (Digital Versatile Disc, (DVD)) entegreli kavramlar ve kavram kümeleri olarak ta tasarlanmıştır. Çalışmanın ilk aşamasında hem internet ortamında hem de Biyoloji Eğitimi materyal geliştirme odasında kayıtlı 1000 tane bilimsel film arşivinden 72 tane teknoloji kavramlarını içeren film tespit edilmiştir. Bu kavramlar antik teknoloji ve günümüz teknolojisi olarak iki grupta sınıflandırılmıştır. Ayrıca Yüzüncü Yıl Üniversitesi Ferit Melen Kütüphanesinde toplu veri taramada, araştırma konusu ile ilgili İngilizceden çevrilen makaleler, resimler, filmler için 30 adet web sitesi ve 55 adet bilim teknik makalesi taranarak kullanılmıştır. Çalışma için kullanılan filmler sanal ortamda Ulead Media programı ile kesilmiş olup Adobe Macromedia Flash Encoder ile .mpg formatından.flv dosyasına çevrilmiştir. Flv uzantılı dosyalar Macromedia Flash 8'le düzenlenerek ilgili kavramın tanımı, süresi ve hangi kavramlarla birlikte kesildiğini belirten kavram kümesine farklı fonda yazı renkleri ile film çerçevesinin altına yapıştırılarak .swf olarak hazırlanmıştır. Dreamweaver 8 Web Editörü

\footnotetext{
*Bu çalışma Antik ve günümüz teknolojisiyle ilgili temel kavramların görsel, işitsel, yazımsal ve zamansal olarak eğitim amaçlı hazırlanması üzerine bir çalışma adlı yüksek lisans tezinin bir parçasıdır.

** Prof. Dr. Yüzüncü Yıl Üniversitesi, Eğitim Fakültesi, Biyoloji Eğitim Bölümü. nasip@hotmail.com, Orcid ID 0000-00034195-070X

*** MEB de Öğretmen, Erzurum, erhan_acar49@hotmail.com, https://orcid.org/0000-0002-3323-4351

**** Dr. Öğrt. Üyesi/ Muş Alparslan Üniversitesi, Malazgirt Meslek Yüksek Okulu, Çocuk Gelişimi Bölümü. sgnova@windowslive.com, https://orcid.org/0000-0001-5092-0495
}

Gönderim: 17.04.2018 Kabul:15.07.2018 Yayın:10.09.2018


programı yardımı ile kavrama ait internet sayfası oluşturulmuş ve alfabetik sıraya göre düzenlenmiştir. Popüler teknolojik kavramlar ile ilgili seçilip izlenen filmlerin kavramlarını belirten bir kavram kümesi ConceptDraw Office PRO programı kullanılarak yapılmıştır. Tüm bu aşamaların sonunda 849 adet popüler teknoloji kavramı ve kavram kümelerini anlatan görsel, işitsel ve tanımlayıcı bir ders materyali hazırlanmıştır.

Anahtar Kavramlar; Kavramlar, Materyal geliştirme, Popüler teknoloji.

\title{
Visual Material Development in the Education of Popular Concepts of Technology
}

\begin{abstract}
In the study, popular technology concepts and materials were prepared to appeal to more audiences and to make them more perceptible in order to better understand the concepts through 72 films containing with virtual programs. The material is designed as concepts and concept clusters integrated with internet and DVD that will appeal to audiences visually, audibly, spontaneously and temporally. In the first phase of the study, a film containing 72 technology concepts related to the subject was identified from 1000 scientific film archives, both on the internet and in the Biology Education material development room. These concepts are classified in two groups as antique technology and modern technology. Furthermore, in the collection of data in the Ferit Melen Library of Yüzüncü Y1l University, 30 websites and 55 scientific articles were scanned and used for English translated articles, pictures and films about study topic. The films used for the study were cut with Ulead Media program in the virtual environment and converted from .mpg format to .flv file with Adobe Macromedia Flash Encoder. The files with the flv extension are edited with Macromedia Flash 8 and put in a .swf file with different font colors and under the film frame to indicate the concept, the definition of the concept, the duration and what concepts are cut together. With the help of the
\end{abstract}


Dreamweaver 8 Web Editor program, the web page of the concept was created and arranged in alphabetical order. A set of concepts describing the concepts of selected and selected films about popular technological concepts was made using the ConceptDraw Office PRO program. At the end of these stages, a visual, auditory and descriptive course material was prepared describing 849 popular technology concepts and concept clusters.

Keywords: Concepts, Material development, Popular technology

\section{Giriş}

Gelişen ve hızla ilerleyen teknolojinin eğitim ortamında kullanılması veya kullanılan teknolojilerin adaptasyonu özellikle fen eğitiminde önem arz etmektedir (Demirkuş, 2018). Dolayısıyla gelişen teknoloji ile ders içerikleri, muhatapların (öğrenci, öğretmen...) rahat bir şekilde sanal (bilgisayar) ortamda doğru ve amaca uygun bilgiye ulaşma imkânı sağlanacak şekilde hazırlanmalıdır. Ders içeriklerinde ise özelikle kavramların önemi çok büyüktür. Kavramlar anlaşılmadığında konunun da anlaşılması mümkün değildir. Kavramlar ve isimler bilimsel dokunun hücreleri, kavram kümeleri de bilimsel doku gibidirler. Doğru öğrenilmediği zaman doku hasarlı olur ve diğer dokulara da zarar vermeye başlar (Acar, 2015; Gülen ve Demirkuş, 2014).

Kavramlar varlıkları (canlılar, olaylar ve cansızları) ve düşünceleri benzer ve ayırıcı özelliklerine göre gruplandırdığımızda gruplara verilen adlardır (Demirkuş, 2018; Gülen, 2018; Köse, Ayaş ve Taş, 2003). Eğitim öğretim sürecinde kavramlar, kavramsal ilişkiler, kavram öğrenme ve kavramlar arası ilişkilerin derinlemesine öğrenilmesini sağlayan araçlar kullanılarak öğrenildiğinde öğrenmenin gözlemlenebilir bir şekilde değiştiği ve öğrencilerin konuya yönelik analiz, değerlendirme ve sentez gibi üst düzey düşünme biçimlerini 
kullanabildikleri tespit edilmiştir (Demirkuş ve Gülen, 2014b; Taş, Gülen, Öner ve Özyürek, 2015).

Popüler teknolojik kavramlar, günlük hayatımızda sıkça duyduğumuz ve kullandığımız ya da eskiden kullanılan ama halen adı gecen teknolojik kavramları kapsamaktadır (Demirkuş, 2018; Gülen, 2016a). Teknoloji, Yunanca sanat ve bilmek sözcüklerinin birleşiminden oluşmuştur. Teknoloji, insanlar için araç-gereçlerin yapılmasında veya üretilmesinde gerekli bilgi ve yetenek olarak tanımlanabilir. İnsan üretimi olan teknoloji mühendislikten önce ortaya çıkmıştır. Ayrıca teknoloji, bilimin uygulamalı yönü olarak da bilinir (Seferoğlu, 2006; Öztürk, Akdeniz ve Bakırcı, 2017; Yavuz ve Coşkun, 2008).

Tarih boyunca, insanlar istek ve ihtiyaçlarını karşılamak için teknolojiyi geliştirmişlerdir. Bu teknoloji bazen bir mızrak bazen de tekerlek gibi antik olarak karşımıza çıkmaktadır. Günümüz modern teknoloji fen, mühendislik ve matematiğin bir ürünüdür ve teknolojik araçlar bu alanlarda da kullanılmaktadır (Bacanak, Karamustafaoğlu ve Köse, 2003; Honey, Pearson ve Schweingruber, 2014). Teknolojinin eğitimde kullanılması öğrenme ve öğretme sürecinde sistematik ve bütüncül bir şekilde araç-gereç kullanılması olarak görülmektedir (Y1lmaz, Ulucan ve Pehlivan, 2010). Fen eğitiminde teknolojik araç gereçlerin aktif kullanılmasının sağlanması ve kalıcı izli davranış değişikliklerinin meydana getirilmesi hedeflenmektedir. Eğitimde fen ve teknoloji kavramları beraber kullanılmaktadır. Teknoloji ile daha zengin öğrenme ortamları sunabilmek, daha fazla duyu organına hitap edebilmek, bireyin özellikle fen bilimlerine olan ilgisini ve motivasyonunu artmasını ve fen konularına ilişkin eski bilgilerin hatırlanmasını sağlamak fen ve teknoloji disiplinlerinin beraber kullanılmasını gerektirir (Dugger, 1993; Özmen, 2004). Teknolojinin gelişimi ile eğitim alanında birçok araç gereç kullanılmıştır. Her derste ve sınıfta kullanılan geleneksel araçların yanı sıra hesap makineleri, ölçüm araçları (kütle-ağırlık-nem-direnç vs.), mikroskop, teleskop, elektronik 
beyaz panolar, sinema, televizyon, video, dizüstü bilgisayarlar, tablet bilgisayarlar, akıllı telefonlar, internet, kablosuz internet, çevrimiçi kaynaklar, eğitim yazılımları gibi birçok araç kullanılmaktadır (Honey, Pearson ve Schweingruber, 2014). Eğitim programları hazırlanırken yukarıda belirtilen teknolojik araçların kullanımına dikkat edilmektedir.

Mevcut fen program yaklaşımı olan araştırma-sorgulamaya göre fen eğitiminde teknoloji kullanımı, bireyin çevresindeki problemleri tanımlamasını ve bu problemlere uygun çözümler üretmeyi içeren yüksek düzeyli düşünme yeteneklerini geliştirdiği belirtilmektedir (Aktepe ve Aktepe, 2009). Son yıllarda fen eğitiminde özellikle iletişim teknolojileri ile sanal ortamda eğitim olanağının artması fen eğitiminde kolaylık sağladığını göstermektedir (Karasar, 2004). Günümüzde özellikle Fırsatları Artırma Teknolojiyi İyileştirme Hareketi (FATİH) projesi gibi devasa projeler ile eğitim-öğretim ortamında teknolojik araç-gereçlerden faydalanması hedeflenmiştir. Fen eğitiminde de, soyut ve anlaşılması zor kavramların öğretilmesinde, ulaşılması zor olan uzay ve ötesi gibi konuların öğretilmesinde ve tehlike arz eden deney veya simülasyonlarda teknolojinin kullanılmasının eğitime son derece fayda sağladığı görülmektedir (Ayvacı, Bakırcı ve Başak, 2014; Gülen ve Demirkuş, 2014a).

Teknoloji özellikle son yıllarda inovasyon kavramı ile karşımıza çıkmaktadır. İnovasyon "yenilenme" veya "yeni ve değişik bir şey yapmak" olarak belirtilebilir (Yamaç, 2001). Ülkeler ekonomik kalkınmalarını büyük oranda teknolojik yenilikler ile belirlemektedir. $\mathrm{Bu}$ yeniliklerin sürekli olabilmesi için geleceğin mühendislerinin, fen bilimi uzmanlarının, bilim ve teknoloji okur-yazarlarının gelişmesi eğitim ortamında popüler teknolojik kavramların doğru ve etkili öğretilmesine bağlıdır (Yamak, Bulut ve Dündar, 2014). Antik çağ teknolojisi ile örnek, model ve yaratıcılık gibi konularda fikir edinirken günümüz teknolojik imkânların kullanımı ile kalıcı öğrenme ve geleceğe inovatif düşüncelerin yayılması sağlanmaktadır (Gülen, 2016b). Söz konusu bu durum öncelikle eğitim ortamında popüler teknolojik 
kavramlar ile ilgili olan kavramların öğretimi ile başlamalıdır. Bu popüler teknolojik araçlar ile ilgili olan kavramların maliyeti en az ve ulaşılabilir bir materyal kullanımı ile eğitim öğretim hayatına sürmek elzem önem arz etmektedir. $\mathrm{Bu}$ nedenle popüler (antik ve günümüz) teknolojik kavramların eğitiminde sanal programlar kullanılarak internet entegreli kavram öğrenme materyali hazırlanması amaçlanmıştır.

\section{Araştırmanın Önemi}

Kavramlar öğrenilirken sadece yazımsal tanımları ya da sadece görsel, işitsel tanımlarını birbirinden kopuk ve ayrı sunmak kavramların öğrenilmesini kalıcı hale getirmede eksik kalabilir. Bu nedenle kavramların; yazımsal, görsel, zamansal ve işitsel bir ilişki bütünlüğü içersin de bir arada verilmesi, öğrencilerde daha kalıcı öğrenmeyi güçlendirir (Gülen, 2010, Gülen ve Demirkuş, 2014b).

Çalışma sonucunda elde edilen materyal internette bütünleşik olarak sürekli güncellenebilir nitelikte hazırlanması eğitimin geleceği açısından çok büyük önem taşır. Öğretimde kavramların doğru anlaşılması, öğrenilmesi, uygulanması ve kullanılması için; veri toplama, değerlendirme ve işlemesine yönelik değerlendirilebilir yöntem için örnek teşkil etmektedir.

\section{Araştırmanın Amacı}

Popüler teknolojik (antik ve günümüz) kavramların doğru öğrenilmesini ve uygulanmasını sağlamak, bu kavramlar ile ilgili ortaya çıkabilecek kavram yanılgılarını ortadan kaldırmak ve aktif bir şekilde maliyetsiz olarak kullanılabilecek ders materyali hazırlamaktır.

\section{Yöntem}

$\mathrm{Bu}$ çalışma nitel araştırma desenlerine ve materyal geliştirme ilkelerine bağlı olarak hazırlanan betimsel bir doküman incelemesidir. Doküman incelemesi, verilerin olduğu gibi 
ele alınıp belli kriterler ışığında objektif bir şekilde incelenmesi ve analiz edilmesi olarak bilinir (Çokluk, Yılmaz ve Oğuz, 2011). Çalışmadaki kavramlar detaylı ele alınmış ve çeşitli verilerle de desteklenmiştir. Araştırmanın kapsamı, 72 tane film içerisinden popüler teknolojisiyle ilgili temalar baz alınarak ortaya çıkartılan 849 kavramın alan yazının yeteri örneklemlerle betimlendiğini göstermektedir. Popüler teknoloji kavramları, gündelik hayatımızda sıkça adını duyduğumuz, antik ya da günümüz zamana ait teknolojik araçları ifade eder (Demirkuş, 2018). Araştırmada veri toplama aracı olarak sanal bilgisayar programları kullanılmıştır. Veriler içerik analiz yöntemi ile kodlanarak analiz edilmiştir. Kodlamalarda Miles ve Huberman (1994)'ın formülü kullanılarak güvenirlik hesaplanması bulunmuştur. Buna göre 849 kodun 773 tanesi görüş birliği, 76 tanesi görüş ayrılığı ile belirlenmiştir. Bu hesaplamaya göre \% 91 oranında güvenirli kodlama yapılmıştır. Nitekim Miles ve Huberman (1994) göre \% 80 ve yukarısı güvenilir olarak kabul edilmiştir (Arık ve Yılmaz, 2017; Creswell, 2013; Merriam, 2013). İzlenen belgesel filmler içerisinde konu ile alakalı kavramlar kodlanmış ve sanal programlar kullanılarak parçalanmış sonrasında bir materyalde amaca uygun olarak toplanmıştır. Hazırlanan materyalin yukarıda anlatılan güvenirlik çalışmalarına ilaveten Gülen ve Demirkuş’un (2014) yaptı̆̆ı benzer çalışmadaki pilot uygulama güvenirlik çalışmaları da dikkate alınarak düzenlenmiştir. Geçerlilik çalışması da fen bilimleri ders kitapları konu ve kazanımlarına göre düzenlenmiştir. Materyal geliştirme ilkelerine bağlı olarak geçerlilik desteklenmiştir. Ayrıca araştırmanın örneklemi, kavramlar ve açıklamaları, veri toplama ve analiz süreçleri ayrıntılı olarak verilerek geçerlilik güçlendirilmiştir. Çalışmada yapılan analizlerin hepsi alan uzmanı ve doktorasını tamamlamış iki öğretim üyesi ve yüksek lisansını tamamlamış bir öğretmen tarafindan yapılmıştır.

Çalışmanın ilk aşamasında internetten alan yazı ile ilgili edinilen görsel, yazılı, video, vb. bilgilerin kavramsal açıdan bir değerlendirilmesi ve gruplandırılması yapılmıştır. 
Kullanılacak materyallere internet, interaktif ilişkisel linkler atılarak; internet üzerinde yayımlanmak üzere biyoloji web sitesi ve DVD'si doküman olarak hazırlanmıştır. Çalışmanın ikinci aşamasında özellikle TÜBİTAK popüler bilim yayınlarından çalışma ile ilgili 1968-2010 yılları arasında yayımlanan yaklaşı 540 makale incelenerek konu ile ilgili kavramlar ve bilgiler diğer materyallere internet, interaktif ilişkisel linkler atılarak; internet üzerinde yayımlanarak biyoloji web sitesi yayımlanmak üzere hazırlanmıştır. Çalışmanın üçüncü aşamasında film arşivinde popüler teknoloji kavramları içeren, yaklaşık 1000 (yaklaşık 900 saatlik) bilimsel ve belgesel film içerisinden 72 tane film seçilmiştir.

Seçilen filmler tek tek en az ikişer kez izlenmiş, özetleri çıkarılmış ve hangi kavram ve kavram kümelerinin çıkartılacağı not edilmiştir. Sanal Ortamda Ulead Media ile kesilmiş ve ses ve görüntü düzenlemeleri yapılan kavramlara ait filmler Adobe Macromedia Flash Encoder ile .mpg formatından .flv dosyasına çevrilmiştir. Flv uzantılı dosyalar Macromedia Flash 8'le düzenlenerek ilgili kavramın tanımı, süresi ve hangi kavramlarla birlikte kesildiğini belirten kavram kümesine farklı fonda yazı renkleri ile film çerçevesinin altına yapıştırılmıştır. Popüler teknolojik kavramlar ile ilgili seçilen, izlenen filmlerin kavramlarını belirten bir kavram kümesi ConceptDraw Office PRO programı kullanılarak hazırlanmıştır. Macromedia Flash 8 programı kullanılarak .swf olarak hazırlanan bu kavram filmler 849 adettir. Macromedia Dreamweaver 8 Web Editörü ile hazırlanan kavramlar alfabetik sıraya göre düzenlenerek ve ilgili linkler atılarak internet üzerinden yayınlanmak üzere popüler teknolojik kavramlar ile ilgili kavramlar, kavram kümelerini anlatan görsel, işitsel, zamansal ve yazımsal olacak şekilde tanımlayıcı 849 adet kavram film hazırlanmıştır. Özetle birlikte filmin ayrıntılarına yönelik sorular da bu aşamada çıkartılmıştır. İnternetten popüler teknolojik kavramlar ile ilgili yaklaşık 55 makale uygun olacak şekilde disipline edilerek web sayfasında yayına konulmuştur. Aşağıdaki linklerde gerekli verilere ulaşılabilir. 
http://www.biyolojiegitim.yyu.edu.tr/makale.html

http://www.biyolojiegitim.yyu.edu.tr/kf/ea/ea.html

\section{Materyal Geliştirme İlkeleri}

Materyalin hazırlanmasında Yüzüncü Y1l Üniversitesi Eğitim Fakültesi Biyoloji Eğitimi Bölümü film arşivinden 72 bilimsel film (Discovery Channel, National Geographical Channel, History Channel, National Wild Channel, BBC Premium... vb kanallardan kaydedilen bilimsel belgeseller), yine aynı üniversitenin kütüphanesinde popüler teknolojiye ait kavramlarla ilgili İngilizce'den çevrilen 55 tane makale (Bilim Teknik, PCnet ve Chip dergileri makaleleri)ve internetteki arama motorlarından 30 adet film ve resim içeren site kullanılmıştır. Bu dokümanlardan popüler teknolojik kavramlar ile ilgili 849 adet .swf ve 72 adet .pdf kavrama elde edilmiştir.

Materyal, televizyon, bilgisayar, video, fotoğraf makinesi... vb. nesnel araçlar ile Adobe Macromedia Dreamweaver web Editörü, Ulead Media Video Editörü, Flash ve Flash Encoder, ConceptDraw MINDMAP gibi sanal araçlar kullanılarak hazırlanmıştır. Materyalin hazırlanmasında kullanılan sanal ve nesnel programlar ile tüm dokümanlar Demirkuş’tan (2018) izin alınarak hazırlanmıştır. Söz konusu materyal aşağıda belirtilen ilkeler ışığında hazırlanmıştır. Bu ilkeler ile hazırlanan materyal yukarıda tanımlanan uzman görüşü eşliğinde şekillendirilmiştir

1. Anlamlılık ilkesi: Kullanılan kavramların anlam ifadelerine dikkat edilir.

2. Bilinenden başlama ilkesi: Somuttan soyuta, basitten karmaşığa ve bilinenden bilinmeyene ilkesine uyularak kavram seçimi yapılmıştır.

3. Çok örnek ilkesi: Bir kavramın genişliğini göstermek için çok sayıda örnekler vererek sunmak gerekir. 
4. Görelik ilkesi: Özellikler birbirine göre algılanır. Resim ve şekilleri herkes başka şekilde algılamamalı, birbirinden ayırt edebilmelidir.

5. Seçicilik ilkesi: Öğretim materyalindeki önemli elemanları dikkati en çok çekecek şekilde yerleştirmek gerekir.

6. Tamamlama ilkesi: Bir olayın ya da eşyanın tümüne ilişkin çizgileri vermek yerine bir kısmını vermek yeterli olabilir.

7. Fonun Anlamlılı̆̆ ilkesi: Şekil ya da yazıya kavrama uygun anlam katacak bir fon olmalıdir.

8. Kapalılık ilkesi: Şekiller belirgin olmalı, açık ve yarım bırakılmamalı. Özellikle iki boyutlu figürler için şekil tam yapılmalıdır.

9. Birleştiricilik ilkesi: Birbiriyle benzerliği ve yakınlığı olan nesne ve olaylar ilişkili olarak algılanır ve daha iyi hatırlanır.

10. Algıda değişmezlik: Öğrencinin önceden bildiği nesneler çok basit çizgilerle verilebilir.

11. Derinlik ilkesi: Doğadaki varlıklar bize yakın ise gerçek ölçüleri ve renkleriyle görünürler. Aynı varlıklar uzaklaştıkça, küçülüyor ve renkleri de soluyor hissini veriyor.

12. Yenilik ilkesi: Dikkat, özellikle geçirile gelen ve yakın geçmişteki yaşantılara zıt olan durumlara ve yeniye çekilir.

13. Basitlik ilkesi: Dikkati çekmesi ve üzerinde tutması için, bir görsel aracın elemanları karmaşık değil basit olmalıdır.

14.Hedef-davranış ilkesi: Kullanılacak araç, kazanılması öngörülen hedef davranışı oluşturabilecek nitelikte olmalıdır. 
15. Öğrenciye uygunluk: Kullanılacak araç, öğrencilerin özelliklerine (yaş, zekâ ve geçmiş yaşantıların düzenine) uygun olmalıdır (Acar, 2015; Demirkuş ve Gülen, 2017; Demirkuş, Bozkurt ve Gülen, 2017; Gülen ve Demirkuş, 2014b).

\section{Bulgular}

72 adet filmin içeriğine ait, filmle öğretme-öğrenme yöntemi ve kavram kümesi tekniğine uygun özet çıkartılmış ve filmlerin ayrıntılarına yönelik önemli sorular hazırlanmıştır. Her filmden kesilen kavramlardan oluşan kavram kümesi web sayfası (72 adet) hazırlanmıştır (Resim 1).

http://www.biyolojiegitim.yyu.edu.tr/f/accmtz.pdf

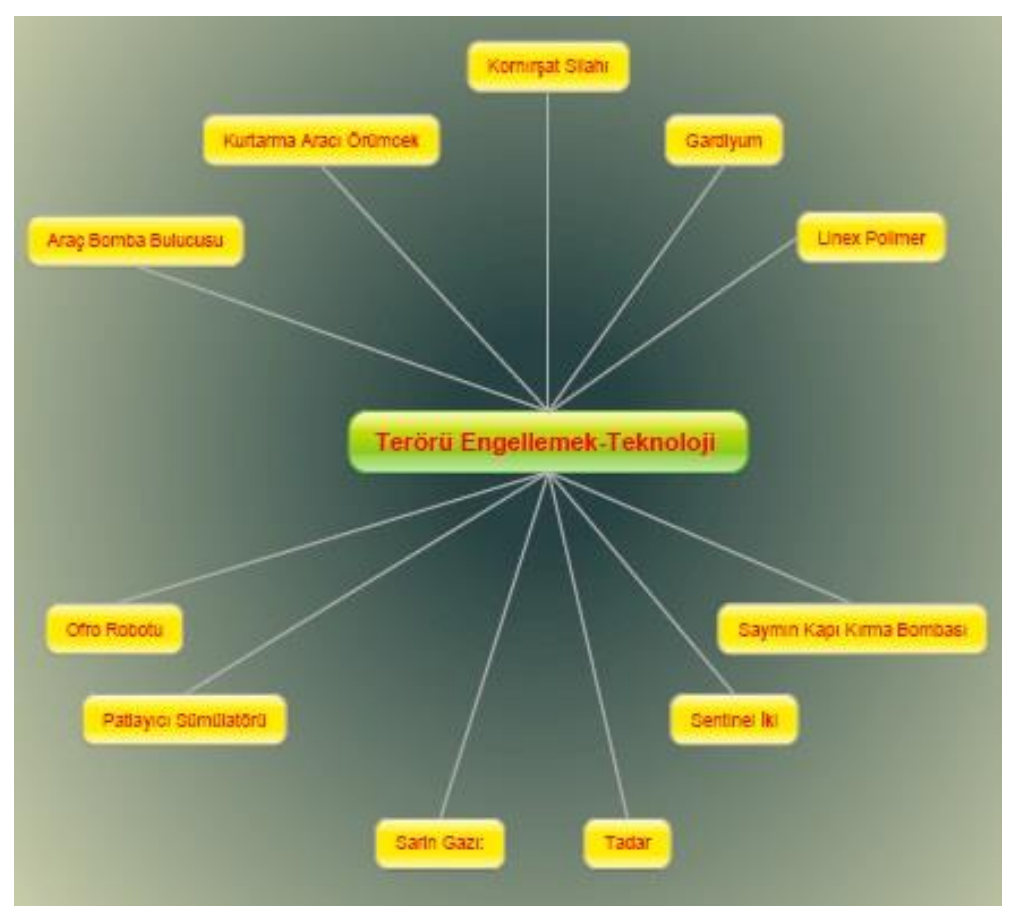

Resim 1: Filmlerden seçilen kavramların oluşturduğu küme

Resim 1'de “Terörü engellemek-Teknoloji” adlı filmden alınan kavram filmlerin oluşturduğu kavram kümesi görülmektedir. Her filmin kavram kümesine ait bir web sayfası ve bu web sayfasından her bir kavram filme linkle ulaşılmaktadır. Her kavrama ait web sayfasında 
bulunan kavramın tanımı, kavram filmi, filmin süresi ve kavram kümesine link atılmıştır $(\operatorname{Resim} 2 ; 3)$.

\section{http://www.biyolojiegitim.yyu.edu.tr/kf/easismograf/easismograf.swf}

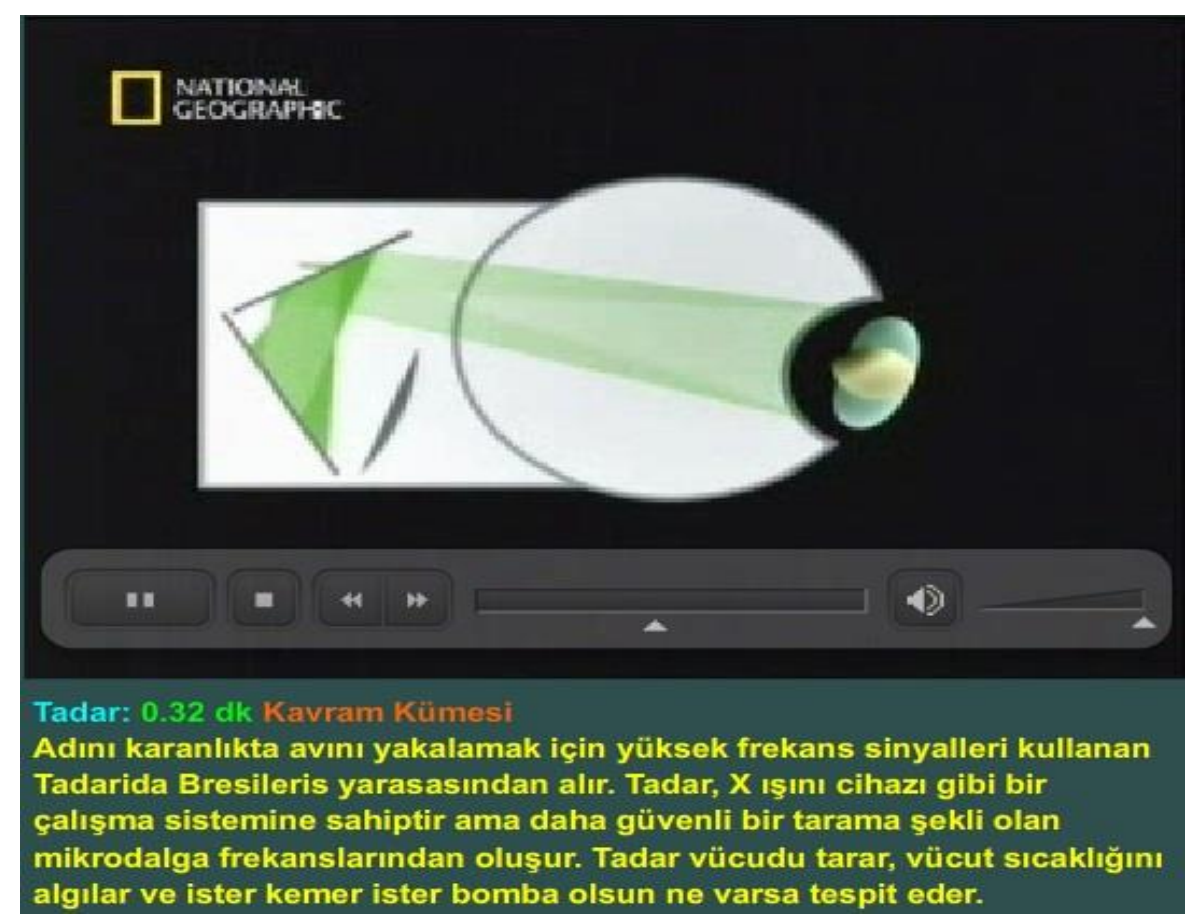

Resim 2. Görsel, işitsel ve yazımsal olarak kavram

Resim 2'de kavram filmin adı, süresi, tanımı ve ilişkili olduğu kavram kümesi uygun font-renk ve linklerle belirtilerek verilmiştir. Söz konusu resimde “Tadar" adı verilen bir teknolojik kavram sunulmaktadır. Bu kavramı tanımlamak için hazırlanan görsel ve işitsel materyalin “ $0,32 ”$ dakikalık bir süresinin olduğu okuyucuya ve izleyiciye sunulmaktadır. Ayrıca kavramın bağlı bulunduğu belgesel film ya da ilişkili olduğu diğer teknolojik kavramlara ulaşabilmek için "Kavram Kümesi” linki de belirtilmiştir. Son olarak resimde belirtilen kavramın “tanımı” yapılmıştır. Bu tanım aşağıda verilmiştir:

“Tadar; adını karanlıkta avını yakalamak için yüksek frekans sinyalleri kullanan Tadarida Bresileris yarasasından alır. Tadar, X ışını cihazı gibi bir çalışma sistemine sahiptir ama daha güvenli bir tarama şekli olan mikrodalga frekanslarından oluşur. Tadar vücudu tarar, vücut sıcaklı̆̆ını algılar ve ister kemer ister bomba olsun ne varsa tespit eder." 
Söz konusu tanıma benzer şekilde diğer kavramlarda tanımlanmıştır. Ayrıca bir kavrama ulaşabilmede kolaylık sağlamak için alfabetik sıralama ve aynı harften olanların aynı sayfada olması sağlanmıştır.

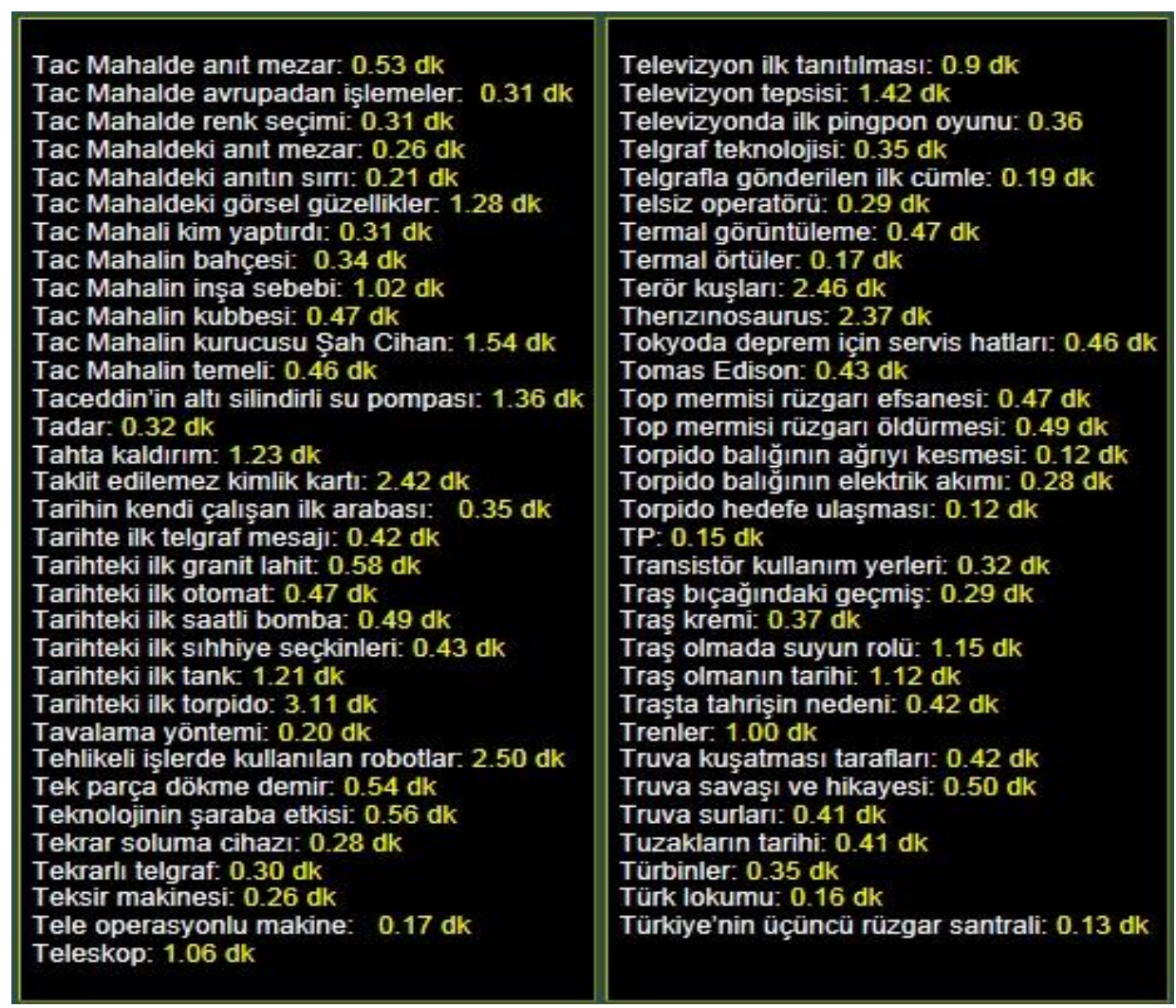

Resim 3: Aynı harfle başlayan popüler teknoloji ile ilgili kavramlar

Resim 3'te " $T$ ” harfi ile başlayan popüler teknoloji kavramlarının gösterildiği ara yuz verilmiştir. Bu sayfadan alfabenin her harfi kadar hazırlanmıştır. Kavram filmlerin isimlerine göre alfabetik sıralama yapılmıştır ve her harfin (W, Q, X dâhil) web sayfası hazırlanmıştır (Resim 4). 


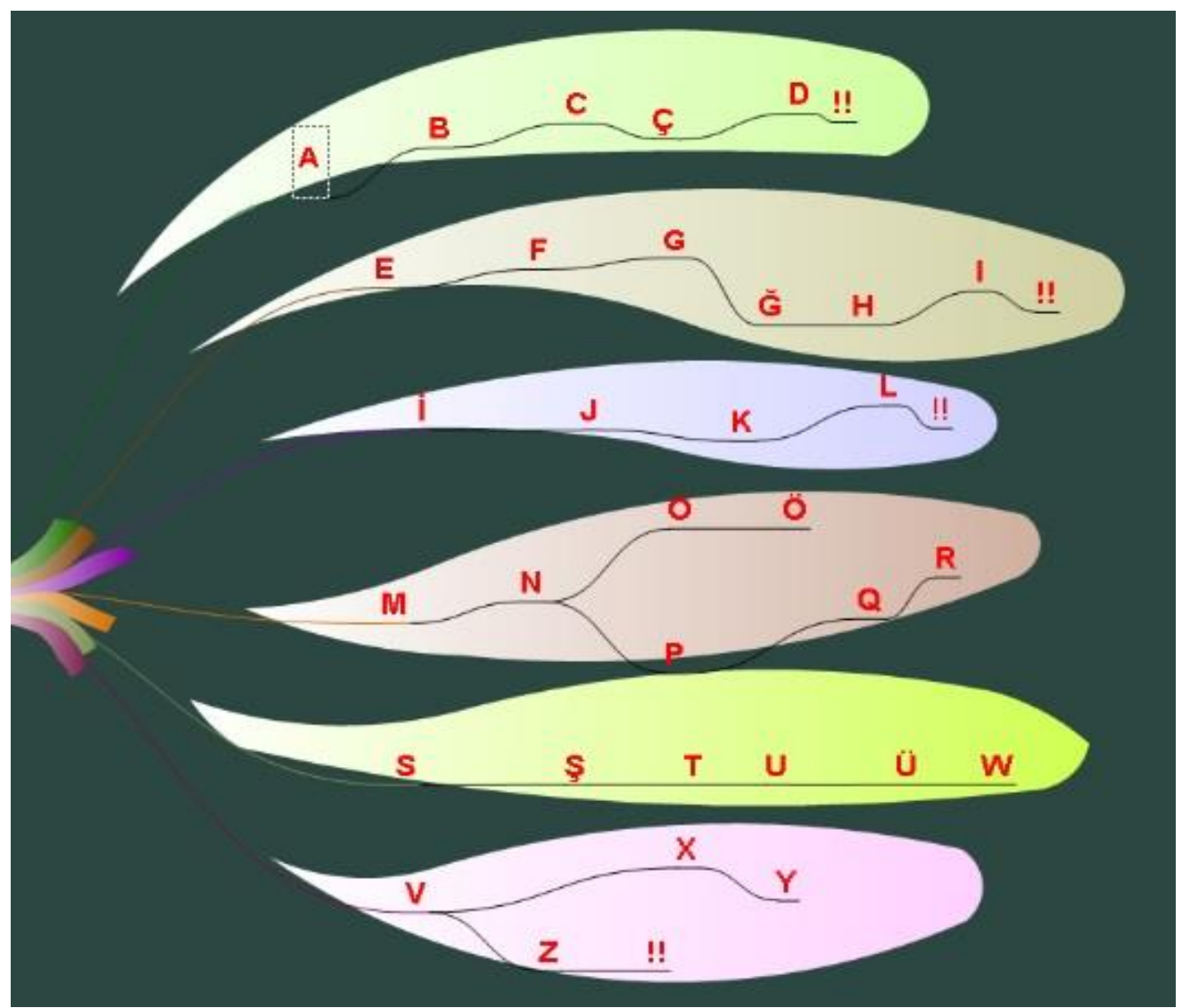

Resim 4. Alfabetik sinıflandırma ile tüm kavramların internet sayfası

Resim 4’te alfabetik olarak hazırlanan sayfaların bulunduğu ana sayfa gösterilmektedir. Buradan istenilen harften istenilen kavrama ulaşılabilmektedir. Çalışma konusu ile ilgili bilim teknik dergisinde yayınlanan 1968-2010 y1lları arasında teknolojiyle ilgili yayınlanan 55 adet makale gözden geçirildikten sonra disipline edilerek internet web sayfaları hazırlanmıştır.

\section{http://www.biyolojiegitim.yyu.edu.tr/makale.html}

Filmlerden elde edilen kavramlar, kitaplardan, internet web sitelerinden, bilim teknikteki kaynak makalelerden, ders notlarından ve Ferit Melen Kütüphanesi veri tabanından elde edilen bilgiler çerçevesinde tüm kavramları denklemsel, tanımsal, yapısal ve ilişkisel olarak bir arada düşünerek vardığımız sonuçlar ve yargılar tezin sonuçlar ve öneriler kısmında sunulmuştur. 72 tane filmin içeriğine ait filmle öğretme-öğrenme ve kavram kümesi yöntemine uygun özet çıkarılmasının ve filmin ayrıntılarına yönelik önemli soruların çıkarılmasının 
nedeni; filmin içeriğinin izleyenin ne kadar işine yarayabileceğini, ne kadar zamanını alabileceğini ve kendisine neler kazandırabileceğini, zaman kaybetmeden yani kestirmeden, önceden bilgi sahibi olmasına yardım etmesi içindir. Sorular da filmin ayrıntılarındaki önemli kısımları vurgulayacak şekilde hazırlanmıştır. Bilimsel filmi kavram filmlere parçalamamızın ya da kavram kümelerine ayırmamız ihtiyaç olunan bir kavrama, tanımına veya kavramla ilgili bir bilgiye ulaşmak için tüm filmi izlemek zorunda kalmamak ve büyük zaman kaybından kurtulmak içindir. Filmleri kavram kümelerine ve kavram tanımlarına ayrılması zaman kazandırdığı gibi her kavram film ve tanım sayfasından filmin tümüne ulaşarak kavramın kullanım alanı içerisinde öğrenilmesine yardımcı olmak için hazırlanmıştır. Her kavram filmi sayfasında; kavram filmine (görsel-işitsel), tanımına, zamansal süresine ve konumsal olarak yer verilmesi kavramı görsel-işitsel (kavram ve kavram kümesi filmi), yazımsal (kavram tanımı ve kavram filmi özeti), zamansal (filmin süresi) ve konumsal (kavram kümesi) olarak daha fazla duyuya hitap ettirmek içindir. Kavramın süresinin verilmesi öğrenciye o kavram için ne kadar süre harcayacağını önceden bilmesi içindir. Kavram kümesine link atılması hem filmin tümüne hem de filmdeki tüm ilişkisel kavramlara bir anda ulaşmak içindir.

\section{http://www.biyolojiegitim.yyu.edu.tr/kf/ea/ea.html}

\section{Sonuç ve Tartışma}

İnternetteki web sitelerinden, Yüzüncü Y1l Üniversitesi Ferit Melen Kütüphanesi toplu veri tabanından, bilim teknik dergisinden ve diğer medya ortamlarından edinilen verilere dayalı olarak konu ile ilgili kavramların görsel-işitsel (kavram ve kavram kümesi filmi), yazımsal (kavram tanımı ve kavram filmi özeti), zamansal (filmin süresi) ve konumsal (kavram kümesi) tanımlarının bir arada veren bir materyal hazırlanmıştır. Bu materyal 849 tane popüler teknoloji 
kavramları içermektedir. Materyali kullananlar kavramı, kavram kümesini ve bilimsel filmin ayrıntılarını öğrenebilmektedirler.

Gülen (2010) yaptığı çalışmada görsel materyallerin öğrenciler tarafindan rahatlıkla kullanılabildiğini ve bu materyallerin öğrenci başarısını artırdığını tespit etmiştir. Chen ve arkadaşları (2007) hazırladıkları sanal materyalin konu kazanımlarının öğretilmesinde etkili olduğunu bulmuşlardır. Taş, Gülen, Öner ve Özyürek (2015)'in yaptıkları çalışmalarda ders ortamında kullanılan görsel materyallerin kavramları anlamlı öğrenmelerini ve bu kavramları yaşantılarında gereksinimleri doğrultusunda kullanabilmelerini sağladığını belirlemişlerdir. Benzer şekilde Gülen ve Demirkuş (2014a; 2014b)'un çalışmalarında sanal programlarla hazırlanan ve sanal ortamda kullanılan, özellikle ulaşılması zor veya tehlikeli kavramların öğretiminde görsel materyallerin önemini belirtmişlerdir. Ayrıca yazarlar bu materyallerin öğrenci başarısını artırdığını tespit etmişlerdir. Günümüzde yapılan pek çok araştırma öğrencilerin bilimsel kavramları anlamaları üzerinedir (Coştu, 2002; Eisen ve Stavy, 1988). Bunun en önemli nedeni ise öğrencilerin bilimsel ve soyut kavramları anlamada zorluk çekmelerinden ileri gelmektedir. Gülen (2016a) yaptığı çalışmada bu tarz kavramların eğitiminde kavramların kavram ilişkilendirme araçları kullanarak veya kavramların görselliğinin artırılması ile kavram eğitiminde istenilen seviyede bir başarı elde edilebileceğini belirtmiştir. Bireylerin kavramı öğrenmeleri; kavramı farklı ortamda uygulayabilmelerini, kavramı çeşitli temsil biçimlerine dönüştürebilmelerini, kavramlar arasındaki ilişkiyi kurabilmelerini ve kavramları ayırt etmeyi sağlamakla ilgilidir (Bütüner ve Gür, 2008). Nitekim modern anlayışta kavramı, nitelikleri öğrenmek için temsiller oluşturma, onları yeni örneklere genelleme ve örnekleri örnek olmayan kalıplardan ayırma olarak tanımlar (Schunk, 2011). Bunlara ek olarak sanal materyallerin sınıf ortamında kullanılmasıyla öğretim sürecini ve öğrenci motivasyonunu güçlendirdiği araştırmalarla tespit edilmiştir (Repenning ve ark., 
2014; Taş, Köse ve Çepni, 2006). Yapılan çalışmalar bilgisayar ve sanal materyallerin öğrenci başarısına ortalama \% 42 oranında, kimya başarısında \% 52, biyoloji başarısında \% 36 ve fizik başarısına \% 23 oranında olumlu etki ettiği belirlenmiştir (Akçay, Tüysüz ve Feyzioğlu, 2003). Yine Gedikoğlu (2005) öğrencinin kendi öğrenme hızına göre yararlanabileceği ve kendi kendine öğrenme ilkesinin bilgisayar teknolojisi ile birleşmesinden dolayı bilgisayar sayesinde kavramların görsel ve işitsel olarak sunulmasının öğrenmenin kalitesini artırdığı ve anlamlı öğrenmenin gerçekleştiği düşünülmektedir. Ayrıca Tüzün ve ark., (2016) çalışmalarında sanal materyallerin öğrencilerin bilişsel gelişimlerini olumlu etkilediğini tespit etmişlerdir. Özellikle kavramların görsel ve işitsel olarak sunulması kavram eğitiminde değişimlere neden olduğu tespit edilmiştir. Nitekim teknolojinin hızla değişmesi kavram eğitiminin değişmesine neden olmuştur. Özellikle fen eğitiminde kavramın bilgisayarlar sayesinde yapılandırılmasının kolaylaşması sağlanmıştır. Fen eğitiminde bolca bulunan soyut ve anlaşılması zor kavramlar anlatılırken öğrencilerin görsel ve düşünsel yapılarını harekete geçirebilecek öğretim aktivitelerinin geliştirilip kullanılması anlamlı öğrenme için oldukça önemlidir (Ertepınar, Demircioğlu, Geban ve Yavuz, 1998; Köse, Ayas, Taş, 2003). Bu araştırmalar çalışmamızın eğitimsel değerini kanıtlar niteliktedir.

Yukarıda bahsi geçen araştırmalar eğitim ortamında gerek nicel gerekse nitel olarak yapılmış ve her biride kavram eğitiminde materyal kullanımı ve bunun olumlu sonuçları üzerinde durmuştur. Benzer şekilde bu çalışma sonucunda eğitim öğretim sürecinde kullanılmak üzere, anlamlı öğrenmeyi artıracak ve öğrenci başarısına etki edecek popüler teknoloji kavramlarını içeren materyal hazırlanmıştır.

Benzer şekilde Chen ve arkadaşları (2007) Dünya'mız ile ilgili hazırlanan sanal materyallerin konu kavramlarının kazanılmasında etkili olduğunu tespit etmiştir. 
Ayrıca Repenning ve arkadaşları (2014) ile Tüzün ve arkadaşlarının çalışmalarına göre bilgisayar yazılımları ile yapılan üç boyutlu materyallerin de üç boyutlu düşünme becerilerine etkisi vardir.

\section{Öneriler}

Sanal materyallerin eğitim öğretim sürecinde kullanılması ve anlamlı öğrenmeyi artıracağı düşünülmektedir. Sadece fen derslerinde değil diğer derslerde de hazırlanabileceği ve kullanılabileceği önerilmektedir. Özellikle ulaşılması zor, tehlikeli ya da pahalı nesnelerin veya varlıklara ait kavramların eğitiminde sanal materyallerin etkili olduğu önerilmektedir.

İlkokul, ortaokul, ortaöğretim ve yükseköğretim de eğitim mutfağında kullanılan temel nesnel ve sanal araçlar (görsel grafik araçları, görsel ve işitsel video araçları, kavram ilişkilendirme araçları) bilgisayar uygulama sınıflarında öğrencilere ders olarak eğitim sürecine yayılması önerilmektedir.

\section{Makalenin Bilimdeki Konumu (Yeri)}

Bu makalenin konumu Matematik ve Fen Bilimleri Eğitimi ve Fen Bilgisi Eğitimi Anabilim Dalıdır

\section{Makalenin Bilimdeki Özgünlüğü}

$\mathrm{Bu}$ makale sanal, ulaşılması zor ve tehlike arz eden kavramların eğitiminde kullanılabilecek sanal ders materyali hazırlama çalışmasıyla özgündür. Kavram öğretimi anlamlı öğrenmenin gerçekleşmesinde önem arz etmektedir. Kavramların görsel, yazımsal ve işitsel olarak sunumunu yapabilecek materyallerin eksikliğinden hazırlanmıştır. Bu makale de yapılan çalışma ile kavram öğretimi yeni bir boyut kazandırılmıştır. 


\section{Kaynakça}

Acar, E. (2015). Antik ve günümüz teknolojisiyle ilgili temel kavramların görsel, işitsel, yazımsal ve zamansal olarak eğitim amaçlı hazırlanması üzerine bir çalışma. Yayınlanmamış Yüksek Lisans Tezi, Yüzüncü Yıl Üniversitesi Eğitim Bilimleri Enstitüsü, Van.

Akçay, H., Tüysüz, C. ve Feyzioğlu, B. (2003). Bilgisayar destekli fen bilgisi öğretiminin öğrenci başarısına ve tutumuna etkisine bir örnek: Mol kavramı ve avogadro sayısı. The Turkish Online Journal of Educational Technology, 2(2), 57-66.

Aktepe, V. ve Aktepe, L. (2009). Fen ve teknoloji öğretiminde kullanılan öğretim yöntemlerine ilişkin öğrenci görüşleri: Kırşehir BİLSEM örneği. Ahi Evran Üniversitesi Kırşehir Eğitim Fakültesi Dergisi, 10(1), 69-80.

Arık, S. ve Yılmaz, M. (2017). Fen bilimleri öğretmen adaylarının çevre sorunlarına yönelik tutumları ve çevre kirliliğine yönelik metaforik algıları. Kastamonu Eğitim Dergisi, 25(3), 1147-1164.

Ayvacı, H. Ş., Bakırcı, H. ve Başak, M. H. (2014). Fatih projesinin uygulama sürecinde ortaya çıkan sorunların idareciler öğretmenler ve öğrenciler tarafından değerlendirilmesi. Yüzüncü Yll Üniversitesi Eğitim Fakültesi Dergisi, 11(1), 20-46.

Bacanak, A., Karamustafaoğlu, O. ve Köse, S. (2003). Yeni bir bakış: Eğitimde teknoloji okuryazarlığı. Pamukkale Üniversitesi Eğitim Fakültesi Dergisi, 2(14), 191-196.

Bütüner, S. Ö. ve Gür, H. (2008). Açılar ve üçgenler konusunun anlamlı öğrenme araçlarından v diyagramları ve zihin haritaları kullanılarak öğretimi. Necatibey Eğitim Fakültesi Elektronik Fen ve Matematik Ë̆itimi Dergisi, 2(1), 1-18.

Chen, C. H., Yang, J. C., Shen, S., \& Jeng, M. C. (2007). A desktop virtual reality earth motion system in astronomy education. Educational Technology \& Society, 10(3), 289-304. 
Coştu, B. (2002). Ortaöğretimin farklı seviyelerindeki öğrencilerin buharlaşma, yoğunlaşma ve kaynama kavramlarını anlama düzeylerine ilişkin bir çalışma. Yayınlanmamış Yüksek Lisans Tezi, Karadeniz Teknik Üniversitesi Fen Bilimleri Enstitüsü. Trabzon.

Creswell, J. W. (2013). Qualitative research methods (Trans. Ed .: Whole, M., \& Demir, S. B.). Ankara: Political Publications Distribution.

Çokluk, Ö., Yılmaz, K. ve Oğuz, E. (2011). Nitel bir görüşme yöntemi: Odak grup görüşmesi. Kuramsal Ĕgitim Bilim, 4(1), 95-107.

Demirkuş, N. ve Gülen, S. (2017). Popüler fizik kavramları içeren görsel ders materyali geliştirme çalışması. Yüzüncü Yıl Üniversitesi Eğitim Fakültesi Dergisi, 14(1), 320-338. http://dx.doi.org/10.23891/efdyyu.2017.12

Demirkuş, N., (2018). Öğretim teknolojisi ve materyallerinin geliştirilmesi ders notları. Yüzüncü Y1l Üniversitesi Eğitim Fakültesi Biyoloji Eğitimi, Van. Erişim tarihi: 17.06.2018.

Demirkuş, N., Bozkurt, T., ve Gülen, S. (2017). Popüler çevre kavramlarının eğitiminde görsel materyal geliştirme çalışması. Ahi Evran Üniversitesi Kırşehir Ĕ̈itim Fakültesi Dergisi (KEFAD), 18(Özel Sayı), 145-157.

Dugger, W.E., (1993). The relationship between technology, science, engineering, and mathematics. American Vocational Association Conference, Nashville, Tn., December.

Eisen, Y. \& Stavy, R. (1988). Student's understanding of photosynthesis. The American Biology Teacher, 50(4), 208-212.

Ertepınar, H., Demircioğlu, H., Geban, Ö. ve Yavuz, D. (Eylül, 1998) Benzeşme ve bilgisayarlı ögretimin mol kavramını anlamaya etkisi. III. Ulusal Fen Bilimleri Eğitimi Sempozyumu, Karadeniz Teknik Üniversitesi, Trabzon. 
Gedikoğlu, O. (2005). Avrupa birliği sürecinde Türk eğitim sistemi: Sorunlar ve çözüm önerileri. Mersin Üniversitesi Eğitim Fakültesi Dergisi, 1(1), 66-80.

Gülen, S. (2010). Popüler fizik kavramları içeren görsel ders materyali geliştirme çalışması. Yayınlanmamış Yüksek Lisans Tezi, Yüzüncü Y1l Üniversitesi Fen Bilimleri Enstitüsü, Van.

Gülen, S. (2016a). Tool of association concept; volume of concept. Participatory Educational Research, Special Issue 2016-II, 45-50. http://dx.doi.org/10.17275/per.16.spi.2.5

Gülen, S. (2016b). Fen-teknoloji-mühendislik ve matematik disiplinlerine dayalı argümantasyon destekli fen öğrenme yaklaşımının öğrencilerin ögrrenme ürünlerine etkisi. Yayınlanmamış Doktora Tezi, Ondokuz Mayıs Üniversitesi Eğitim Bilimleri Enstitüsü, Samsun.

Gülen, S. (2018). Using volume of concept in the class environment. Journal of Technology and Science Education, 8(4), 205-213. https://doi.org/10.3926/jotse.362

Gülen, S. (Kasım, 2015). Tool of association concept; volume of concept. II. International Dynamic, Explorative and Active Learning (IDEAL) Conference, Amasya, Turkey.

Gülen, S., ve Demirkuş, N. (2014b). Görsel materyalin öğrenci başarısına etkisi. Saarbrücken: Türkiye Âlim Kitapları.

Gülen, S., ve Demirkuş, N., (2014a). Güneş sistemi ve ötesi: Uzay bilmecesi ünitesinde, görsel materyalin öğrenci başarısına etkisi. Yüzüncü Yıl Üniversitesi Eğitim Fakültesi Dergisi, 11(1), 1-19.

Honey, M., Pearson, G., \& Schweingruber, H. (2014). STEM Integration in K-12 education; status, prospects, and an agenda for research. Washington: The National Academies Press.

Karasar, N. (2005). Bilimsel araştırma yöntemi. Ankara: Nobel Yayın Dağıtım. 
Köse, S., Ayaş, A., ve Taş, E. (2003). Bilgisayar destekli öğretimin kavram yanılgıları üzerine etkisi: Fotosentez. Pamukkale Üniversitesi Ĕ̆itim Fakültesi Dergisi, 14, 106-112.

Merriam, S. B. (2013). A guide to qualitative research design and practice (Trans.Turan, S.). Ankara: Nobel Publishing.

Miles, M., \& Huberman, A. (1994). Qualitative data analysis. Thousand Oaks, CA: Sage Publications.

Özmen, H. (2004). Fen öğretiminde öğrenme teorileri ve teknoloji destekli yapılandırmacı (constructivist) öğrenme. The Turkish Online Journal of Educational Technology, 3(1), 100-111.

Öztürk, M., Akdeniz, A.R., \& Bakırcı, H. (2017). Bilgisayar destekli öğretim uygulamalarının ortaokul öğrencilerinin bilimsel düşünme becerilerine etkisi. YYÜ Ĕgitim Fakültesi Dergisi, 14(1), 611-639. http://dx.doi.org/10.23891/efdyyu.2017.24

Repenning, A., Webb, D., Brand, C., Gluck, F., Grover, F., Miller, S., Nickerson, H.,\& Song, M. (2014). Beyond minecraft facilitating computational thinking through modeling and programming in 3D. IEEE Computer Graphics and Applications, 14, 68-71.

Schunk, D. H. (2011). Eğitimsel bir bakışla öğrenme teorileri (Çev. Edr: Muzaffer Şahin). Ankara: Nobel yayıncılık (Çalışmanın orijinal basım tarihi, 2009).

Seferoğlu, S. S. (2006). Öğretim teknolojileri ve materyal tasarımı. Ankara: Pegem A Yayınc1lik.

Selimoğlu, C., Demirkuş, N., ve Gülen, S. (2015). Öğretmen adaylarının öğrencilik yıllarında karşılaştıkları istenmeyen davranışların incelenmesi ve çözüm önerilerinin belirlenmesi. Yüzüncü Yll Üniversitesi Eğitim Fakültesi Dergisi, 12(1), 164-182. 
Taş, E., Gülen, S. Öner, Z., ve Özyürek, C. (2015).The effects of classic and web-designed conceptual change texts on the subject of water chemistry. International Electronic Journal of Elementary Education, 7(2), 263-280.

Taş, E., Köse, S., ve Çepni, S. (2006). Bilgisayar destekli öğretim materyalinin fotosentez konusunu anlamaya etkisi. Internatinal Journal of Environmental and Science Education, 1(2), 163 - 171.

Tüzün, H., Alsancak-Sirakaya, D., Altintaş-Tekin A. ve Yaşareren, S. (2016). An investigation of presence in three-dimensional multi-user virtual environments. H. U. Journal of Education, 31(3): 475-490. DOI: 10.16986/HUJE.2016015867

Yamaç, K. (2001). Nedir bu inovasyon? Bilim, Eğitim ve Düşünce Dergisi. 1(3), 6-7.

Yamak, H. Bulut, N., ve Dündar S. (2014). 5. sınıf öğrencilerinin bilimsel süreç becerileri ile fene karşı tutumlarına FeTeMM etkinliklerinin etkisi. Gazi Üniversitesi Gazi Eğitim Fakültesi Dergisi, 34(2), 249-265.

Yavuz, S., ve Coşkun, A. E. (2008). Sınıf öğretmenliği öğrencilerinin eğitimde teknoloji kullanımına ilişkin tutum ve düşünceleri. Hacettepe Üniversitesi Eğitim Fakültesi Dergisi, 34, 276-286.

Y1lmaz, İ., Ulucan, H., ve Pehlivan, S. (2010). Beden eğitimi öğretmenliği programında öğrenim gören öğrencilerin eğitimde teknoloji kullanımına ilişkin tutum ve düşünceleri. Ahi Evran Üniversitesi Ĕ̈itim Fakültesi Dergisi, 11(1), 105-118.

\section{Summary}

Visual Material Development in the Education of Popular Concepts of Technology 
Problem Statement: The education of abstract and hard-to-reach concepts is important in education. Visualization of these concepts will facilitate learning. Old and contemporary technologies are known as popular technological concepts. This study was conducted because of the lack of teaching these concepts to students in a meaningful way. It consists of 72 films and documents that contain popular technology concepts in the study. Virtual programs have been used to better understand these concepts and make them more perceptible. These programs ensure that the material is more appealing to the senses. The material will appeal to the senses more visually, audibly, spontaneously and temporally. As well as internet and DVD integrated concepts and concept clusters. The films used for the study were cut with Ulead Media program in the virtual environment and converted from .mpg format to flv file with Adobe Macromedia Flash Encoder. The files with the .flv extension are edited with Macromedia Flash 8 and put in a .swf file with different font colors and under the film frame to indicate the concept, the definition of the concept, the duration and what concepts are cut together. With the help of the Dreamweaver $8 \mathrm{Web}$ Editor program, the web page of the concept was created and arranged in alphabetical order. A set of concepts describing the concepts of selected and selected films about popular technological concepts was made using the ConceptDraw Office PRO program. At the end of these stages, a visual, auditory and descriptive course material was prepared describing 849 popular technology concepts and concept clusters.

Purpose of the Study: To provide correct learning and application of popular (ancient and contemporary) technological concepts, to remove the misconceptions that may arise about these concepts, and to prepare lesson material that can be actively used without cost.

Method(s): This study examines a descriptive document based on material development principles. A document review is known as the examination of the data and the examination 
and analysis of the subject in an objective way (Çokluk, Yılmaz and Oğuz, 2011). The concepts in the study are discussed in detail and supported by various sources. In addition, it shows that the field text of 849 concepts, which are revealed in 72 films based on the themes related to popular technology, are described by the experimental samples. Materials were developed with material development principles in the study.

Findings and Discussions: A summary of 72 film contents, with the film teaching-learning method and concept clustering technique, has been produced. Important questions about the details of the films have been prepared. A set of concept web pages (72) consisting of concepts that were cut from each film were prepared.

\section{http://www.biyolojiegitim.yyu.edu.tr/f/accmtz.pdf}

A web page of each film concept set and each concept from this web page can be reached by link. The definition of the concept found on the web page of each concept is linked to the concept film, the film duration and concept set.

http://www.biyolojiegitim.yyu.edu.tr/kf/easismograf/easismograf.swf

Alphabetical ordering was made according to the names of concept films, and each (including $\mathrm{W}, \mathrm{Q}, \mathrm{X})$ web page was prepared.

http://www.biyolojiegitim.yyu.edu.tr/kf/ea/ea.html

Between 1968 and 2010, published in the scientific journal published on the subject of the study, 55 articles on technology were examined and then disciplined and internet web pages were prepared.

\section{http://www.biyolojiegitim.yyu.edu.tr/makale.html}

Gülen (2010) found that visual materials can be easily used by students and that these materials increase students' success. Taş, Gülen, Öner and Özyürek (2015) have determined that the visual materials used in the course environment enable meaningful learning of concepts and 
their use in the context of their needs in their lives. Likewise, Gülen and Demirkuş (2014a; 2014b) emphasized the importance of visual materials in the teaching of difficult or dangerous concepts prepared with virtual programs in their work.

The researches mentioned above have been done qualitatively and quantitatively in the educational environment. Each of them emphasized the use of materials and its positive results in concept education. Likewise, this work has produced a material that includes popular technology concepts that will enhance meaningful learning and influence student achievement, to be used in the educational process.

Conclusions and Recommendations: The material which gives a combination of audiovisual, written, temporal and spatial definitions of the related concepts that based on the data obtained from websites on the internet, Yuzuncu Yil University Ferit Melen Library is a collective database, from the journal scientific technical and from other media. This material contains 849 popular technology concepts. Those who use the material can learn the concept, the set of concepts, and the details of scientific movie. It is considered that virtual materials will be used in the education and training process and will increase meaningful learning. It is suggested that virtual materials are particularly effective in the education of difficult or dangerous or expensive objects or concepts of assets.

Keywords: Concepts, Material development, Popular technology 